\title{
Ultra high temperature latent heat energy storage and thermophotovoltaic energy conversion
}

\author{
Alejandro Datas ${ }^{(*)}$, Alba Ramos, Antonio Martí, Carlos del Cañizo and Antonio Luque \\ Instituto de Energía Solar - Universidad Politécnica de Madrid, Madrid, 28040, Spain \\ ${ }^{(*)}$ corresponding autor: a.datas@ies-def.upm.es
}

Keywords: LHTES (latent heat thermal energy storage), high temperature, thermophotovoltaics, silicon, boron, PCM (phase change materials), CSP (concentrated solar power).

\begin{abstract}
A conceptual energy storage system design that utilizes ultra high temperature phase change materials is presented. In this system, the energy is stored in the form of latent heat and converted to electricity upon demand by TPV (thermophotovoltaic) cells. Silicon is considered in this study as PCM (phase change material) due to its extremely high latent heat $(1800 \mathrm{~J} / \mathrm{g})$, melting point $\left(1410^{\circ} \mathrm{C}\right)$, thermal conductivity $(\sim 25 \mathrm{~W} / \mathrm{m}-\mathrm{K})$, low cost (less than $\$ 2 / \mathrm{kg}$ or $\$ 4 / \mathrm{kWh}$ ) and abundance on earth. The proposed system enables an enormous thermal energy storage density of $\sim 1$ $\mathrm{MWh} / \mathrm{m}^{3}$, which is 10-20 times higher than that of lead-acid batteries, 2-6 times than that of Li-ion batteries and 5-10 times than that of the current state of the art TES systems utilized in CSP (concentrated solar power) applications. The discharge efficiency of the system is ultimately determined by the TPV converter, which theoretically can exceed 50\%. However, realistic discharge efficiencies utilizing single junction TPV cells are in the range of 20-45\%, depending on the semiconductor bandgap and quality, and the photon recycling efficiency. This concept has the potential to achieve output electric energy densities in the range of $200-450 \mathrm{kWh} / \mathrm{m}^{3}$, which is comparable to the best performing state of the art Lithium-ion batteries.
\end{abstract}




\section{$\underline{\text { Nomenclature list }}$}

$A_{c} \quad$ TPV cells total area $(\mathrm{m} 2)$

$c_{p s} \quad$ heat capacity of solid PCM (J/g-K)

$c_{p l} \quad$ heat capacity of liquid PCM (J/g-K)

$c \quad$ speed of light $(\mathrm{m} / \mathrm{s})$

$\dot{E} \quad$ radiative energy flux $(\mathrm{W} / \mathrm{m} 2-\mathrm{sr})$

$E_{\text {tot }}$ energy stored instantaneously in the PCM in the form of specific and latent heat (J)

$h \quad$ Plank constant (Js)

$k \quad$ Boltzmann constant $(\mathrm{J} / \mathrm{K})$

$k_{l} \quad$ thermal conductivity of liquid PCM (W/m-K)

$k_{s} \quad$ thermal conductivity of solid PCM (W/m-K)

$L \quad$ container length (m)

$L_{f} \quad$ latent heat $(\mathrm{J} / \mathrm{g})$

$\dot{N} \quad$ photon flux (\#photons/m2-sr-sec)

$n_{s} \quad$ refraction index of the semiconductor

$P_{e l} \quad$ TPV output electrical power (W)

$Q_{l} \quad$ heat flux in the liquid PCM (W)

$Q_{s} \quad$ heat flux in the solid PCM (W)

$R_{1} \quad$ distance from center to the emitter (m) 
$R_{2} \quad$ distance from center to the outer container wall (m)

$r_{m} \quad$ distance from center to the solid-liquid front (m)

$t$ time (s)

$T_{1} \quad$ temperature at the emitter $(\mathrm{K})$

$T_{2} \quad$ temperature at PCM-wall boundary (K)

$T_{m} \quad$ melting temperature of PCM (K)

$T_{c} \quad$ TPV cells temperature (K)

$V \quad$ TPV cell voltage (V)

$\varepsilon_{G} \quad$ TPV cell semiconductor bandgap (eV)

$\varepsilon \quad$ photon energy $(\mathrm{eV})$

$\rho \quad$ density $(\mathrm{g} / \mathrm{m} 3)$

$\rho_{B R} \quad$ reflectivity of the back-surface reflector in TPV cell

$\eta_{\text {int }} \quad$ internal photoluminescence quantum efficiency of the TPV cell

$\eta_{\text {ext }}$ external photoluminescence quantum efficiency of the TPV cell 


\section{Introduction}

LHTES (latent heat thermal energy storage) employs energy to cause the phase change transition in a material that subsequently stores energy in the form of latent heat. That material is referred to as PCM (phase change material) and is the key element determining the overall performance of the storage system. PCMs promises one of the highest energy densities and lowest costs of existing TES materials [1], [2]. However, current LHTES solutions are subject to a very low heat extraction rate from the storage medium, which is attributed to the low solid-phase thermal conductivity and moderate latent heat of PCMs. Current research efforts focus on developing relatively sophisticated PCM encapsulation so that thermal conductivity is notably enhanced [1], [3]-[6]. However, these strategies inherently have a lower energy density potential, since part of the volume is dedicated to the PCM host.

An alternative solution consists of directly using PCMs with higher thermal conductivity and latent heat. As a general rule, the heat of fusion of materials increases with melting temperature [1], [7]; thus, there is an interest on moving towards higher melting point PCMs. However, in TES for power generation there is a maximum temperature imposed by the heat transfer fluid (HTF) that is used to carry the heat from the PCM to the heat engine, which degrades at high temperatures. Maximum temperatures are typically below $500{ }^{\circ} \mathrm{C}$ [8]. Other technological options exist though; such as thermophotovoltaics (TPV) [9], [10], thermionic [11] or hybrid thermionic-photovoltaic [12] devices that do not require HTFs and consequently have the potential to operate at extraordinary high temperatures.

Previous works have proposed conceptual system designs for solar thermal energy storage based on very high melting point $\mathrm{PCMs}$, such as pure silicon and boron (melting points of $1410^{\circ} \mathrm{C}$ and $2076^{\circ} \mathrm{C}$, respectively) and TPV converters [13]-[19]. The first experiments on molten silicon for TES applications have been recently carried out at the University of South California with the aim of developing a solar thermal propulsion system for microsatellites [20]. The container damage due to freezing expansion of pure silicon was the most relevant engineering concern. Besides, a highly asymmetric freezing profile was observed due to the use of non-adiabatic container walls, which produced regions of molten silicon encased in solid silicon that ultimately resulted in high stress and container damage. It is worth noting that these issues could be solved in future designs by several means, such as using quasi-adiabatic container walls, i.e. improved container thermal insulation, or reducing the container fill factor [20]. In the opinion of the authors, an especially interesting solution consists on using silicon alloys instead of pure silicon, in order to reduce the 
freezing expansion coefficient of the PCM. We believe that, among all the possibilities, the siliconboron system is particularly interesting due to the extremely high latent heat of boron $(4650 \mathrm{~J} / \mathrm{g})$ and the moderately low melting temperature $\left(1385^{\circ} \mathrm{C}\right)$ for the eutectic $\mathrm{Si}_{0.92} \mathrm{~B}_{0.08}$ [21], [22]. Besides, the silicon lattice parameter contracts upon alloying with boron [21], which suggests that freezing expansion issues could be eliminated. Other practical concern is the thermo-chemical compatibility between the container and the PCM at those high temperatures. A variety of refractory materials have been extensively used for casting solidification of all kind of metals at high temperatures, including silicon and boron. Some examples are $\mathrm{BN}$ (used in [20]) $\mathrm{SiC}$ and $\mathrm{Si}_{3} \mathrm{~N}_{4}$. In these cases, important selection criteria are the wetability, solubility and reactivity of the container with the PCM, along with evaporation and oxidation of the PCM in oxygen-rich atmospheres. Thus, it is still needed an extensive research on the compatibility of these materials for the particular application of LHTES, especially concerning cycling and long term reliability.

In this work we present a conceptual LHTES system design for both S2H2P (solar-to-heat-topower), commonly referred to as CSP (concentrated solar power), and P2H2P (power-to-heat-topower) applications. Notice that other $\mathrm{P} 2 \mathrm{H} 2 \mathrm{P}$ concepts have been previously proposed to store the excess of electricity in the grid and co-generate heat and electricity [23]. The concept presented in this paper is based on the same operation principles than previously proposed systems in [13]-[19], i.e. high temperature PCM and TPV energy conversion. The proposed system differentiates from the previous designs in its geometrical configuration, which facilitates the thermal insulation of the PCM and the integration of an independent (mobile) TPV generator, providing a tunable power discharge rate (from zero to full-discharge mode). We assess this concept theoretically to predict its performance under several assumptions, which range from idealistic (to provide the upper bounds of this concept) to more realistic, to provide its actual short-term potential.

\section{System description}

Figure 1 shows two possible configurations of the LHTES system presented in this paper for $\mathrm{P} 2 \mathrm{H} 2 \mathrm{P}$ [24] (left-hand side) and S2H2P or CSP (right-hand side) applications. In the P2H2P case, an electric heating system is used for melting the PCM. Among all the possible options, an inductive electric heater could be used if the PCM is magnetic or electrically conductive (e.g. iron or metallurgical silicon). Other options include resistive or microwave heating. In any case, electrical energy is stored in the form of the latent heat within the PCM. In the S2H2P case (right-hand side in Figure 1); concentrated solar power heats the inner walls of the vessel containing the PCM. If the sunlight concentration factor is high enough [13], [14] (above 1000 suns) the solar heat will produce 
the melting of the PCM and consequently, solar energy will be stored in the form of latent heat. Other arrangements not illustrated in this paper may use the waste heat from high temperature industrial processes or other kinds of electric heating.

In both cases of Figure 1 the stored heat is released in the form of electricity by using a TPV converter, which comprises a number of infrared sensitive photovoltaic cells that directly produce electricity from radiant heat. In contrast to conventional heat engines, the contact-less nature of TPV converters enable extremely high temperature operation, which is essential for this kind of systems. Besides, TPV can provide extremely high power densities (power-to-weight and power-tovolume ratio) at low maintenance costs (neither moving parts nor working fluids within the converter) along with silent operation, which is important for decentralized ES applications. Furthermore, the TPV conversion efficiency is very high, potentially exceeding $50 \%$ due to the possibility of sub-bandgap photon recycling, which can be accomplished, for instance, by using reflectors in the back side of the TPV cells [25].

When electricity is demanded from the LHTES system, the TPV generator is moved in the cylindrical cavity formed by the inner walls of the vessel, from now-on referred to as emitter (Figure 1). Then, the TPV converter is irradiated by the emitter, which is in direct contact with the molten PCM, and produces electricity. During this process, the PCM progressively solidifies creating a crust of solid around the emitter. This crust difficults the flow of heat from the liquid PCM to the emitter. In this concern, the higher solid-phase thermal conductivity of silicon PCM enormously mitigates the impact of this effect on the output system power. Notice that these systems have the possibility of delivering not only electricity, but also heat from the TPV cells cooling, which might be beneficial in some particular applications such as in domestic heating, where the output coolant temperatures of $40-70^{\circ} \mathrm{C}$ match perfectly with the heating temperature requirements.

From the previous description, it is evident that the energy density (stored energy per unit of volume) and the specific energy (stored energy per unit of weight) of these systems relies on the latent heat of the PCM. Besides, the PCM melting temperature determines the attainable TPV conversion efficiency and power density $\left(\mathrm{W} / \mathrm{cm}^{2}\right)$. Thus, high melting point and latent heat are desirable. As explained above, among all the possible candidates, silicon and boron stand out as particularly interesting materials due to their extremely high latent heats $(1800 \mathrm{~J} / \mathrm{g}$ and $4650 \mathrm{~J} / \mathrm{g}$, respectively, see Figure 2). Silicon is advantageous from the practical point of view due to its higher thermal conductivity $(25-130 \mathrm{~W} / \mathrm{mK})$ and moderate melting point $\left(1410^{\circ} \mathrm{C}\right)$ if compared with boron 
(thermal conductivity below $30 \mathrm{~W} / \mathrm{mK}$ and melting point of $2076^{\circ} \mathrm{C}$ ) [13], [26], [27]. Besides, silicon is abundant (second most abundant element on earth) and has low cost $(\sim 1.7 \$ / \mathrm{kg})$. As described above, silicon-boron alloys are particularly interesting due to their potential to achieve extremely high latent heat, moderate melting temperature and lower freezing expansion coefficient than pure silicon. However, for the sake of concreteness in this paper we will use the latent heat and thermal conductivity values of pure silicon. The analysis of other promising PCMs will be considered in future works.

\section{System model}

In order to describe the transient performance of the LHTES system, we assume a quasi-1D analytical model in which the solid-liquid interface is a moving cylinder at a distance $r_{\mathrm{m}}(t)$ from the axial center of the system (Figure 3). To solve the problem we follow the quasi-stationary approach used in [15] assuming an adiabatic (loss-less) container and neglecting natural convection in the liquid. Natural convection in the liquid can be disregarded, as we will see later, due to the very low temperature gradient in the liquid silicon, which leads to a very small variation of the silicon density. Due to the later assumption the 1D-Fourier conduction law applies to describe the heat flow in both liquid and solid phases:

$$
Q_{l, s}=2 \pi r L k_{l, s} \frac{d T}{d r}
$$

By integrating (1) in the solid and liquid we obtain the following expressions for the temperatures $T_{1}\left(r=R_{1}\right)$ and $T_{2}\left(r=R_{2}\right)$ as a function of the melting temperature $\left(T_{\mathrm{m}}\right)$

$$
\begin{aligned}
& T_{1}=T_{m}-\frac{Q_{s}}{2 \pi L k_{s}} \ln \left|\frac{r_{m}(t)}{R_{1}}\right| \\
& T_{2}=T_{m}+\frac{Q_{l}}{2 \pi L k_{l}} \ln \left|\frac{R_{2}}{r_{m}(t)}\right|
\end{aligned}
$$

where $k_{\mathrm{s}}$ and $k_{1}$ are the thermal conductivities of the solid and liquid PCM, respectively. Due to the assumption of adiabatic container, the difference between the energy transferred from the liquid to the solid equals the energy employed in performing the phase change of a the PCM contained in between $r_{\mathrm{m}}(t)$ and $r_{\mathrm{m}}(t+\Delta t)$, which leads to:

$$
\left(Q_{l}-Q_{s}\right) \Delta t=2 \pi L L_{f} \rho_{l} r_{m}(t)\left(r_{m}(t+\Delta t)-r_{m}(t)\right)
$$


where $L_{\mathrm{f}}$ and $\rho_{1}$ are the latent heat of fusion and the density of the liquid PCM, respectively. An additional equation is obtained analyzing the radiative exchange between the emitter surface $\left(r=R_{1}\right)$ and the TPV converter. This analysis has already been done in [25] and results in the following equation

$$
Q_{s} / \pi=-\dot{E}\left(0, \infty, T_{1}, q V\right)+\dot{E}\left(\varepsilon_{G}, \infty, T_{c}, q V\right)+\frac{\rho_{B R}}{1-\rho_{B R}} \dot{E}\left(0, \infty, T_{1}, q V\right)
$$

where

$$
\dot{E}\left(\varepsilon_{1}, \varepsilon_{2}, T, \mu\right)=\frac{2}{h^{3} c^{2}} \int_{\varepsilon_{1}}^{\varepsilon_{2}} \frac{\varepsilon^{3} d \varepsilon}{\exp [(\varepsilon-\mu) / k T]-1}
$$

is the radiative energy flux emitted by a surface at temperature $T$ and with chemical potential $\mu=q V$ (being $V$ the voltage of the TPV cells) in vacuum, in the spectral interval $\left(\varepsilon_{1}, \varepsilon_{2}\right)$, in the normal direction and per unit of solid angle. Equation (5) is valid under the assumption of sharp cut-off TPV cell absorptivity (from $100 \%$ to $0 \%$ ) at the bandgap edge $\left(\varepsilon_{\mathrm{G}}\right)$ and assumes a unity view factor between the emitter and the cells and a reflector of reflectivity $\rho_{\mathrm{BR}}$ located on the back side of the TPV cells.

Finally, due to adiabatic container the total energy stored in the PCM is delivered only by heat radiation through the emitter surface, which leads to

$$
E_{t o t}(t+\Delta t)=E_{t o t}(t)-Q_{s} \Delta t
$$

where $E_{\text {tot }}$ is the total thermal energy stored in the PCM including both specific and latent heat:

$$
E_{t o t} /(2 \pi L)=\rho_{s} c_{p s} \int_{R_{1}}^{r_{m}} r T_{s}(r) d r+\rho_{l} c_{p l} \int_{r_{m}}^{R_{2}} r T_{l}(r) d r+\rho_{l} L_{f}\left(R_{2}^{2}-r_{m}^{2}\right) / 2
$$

Integrals in (8) can be analytically solved by introducing the expressions for $T_{\mathrm{s}}(r)$ and $T_{1}(r)$ obtained from the integration in (1):

$$
\begin{gathered}
\int_{R_{1}}^{r_{m}} r T_{s}(r) d r=\frac{1}{2}\left[r_{m}^{2} T_{m}-R_{1}^{2} T_{1}-\frac{Q_{s}}{4 \pi L k_{s}}\left(r_{m}^{2}-R_{1}^{2}\right)\right] \\
\int_{r_{m}}^{R_{2}} r T_{l}(r) d r=\frac{1}{2}\left[R_{2}^{2} T_{2}-r_{m}^{2} T_{m}-\frac{Q_{l}}{2 \pi L k_{l}}\left(r_{m}^{2}-R_{2}^{2}\right) \cdot\left(2 \ln \left|r_{m}\right|-0.5\right)\right]
\end{gathered}
$$


The equations (2-5) and (7) can be solved numerically to obtain $T_{1}, T_{2}, Q_{1}, Q_{\mathrm{s}}$ and $r_{\mathrm{m}}(t+\Delta t)$. Finally, the output power from the TPV converter is given by [25]

$$
P_{e l}=\pi A_{c} q V \times\left\{\dot{N}\left(\varepsilon_{G}, \infty, T_{1}, 0\right)-\left[1+2 n_{s}^{2}\left(\frac{1-\rho_{B R}}{2}-\frac{1-\eta_{\text {int }}}{\eta_{\text {int }}}\right)\right] \dot{N}\left(\varepsilon_{G}, \infty, T_{c}, q V\right)\right\}
$$

where

$$
\dot{N}\left(\varepsilon_{1}, \varepsilon_{2}, T, \mu\right)=\frac{2}{h^{3} c^{2}} \int_{\varepsilon_{1}}^{\varepsilon_{2}} \frac{\varepsilon^{2} d \varepsilon}{\exp [(\varepsilon-\mu) / k T]-1}
$$

has the same meaning than $E$ but for the photon flux instead of the energy flux, $n_{\mathrm{s}}$ is the refraction index of the semiconductor and $\eta_{\text {int }}$ is the internal luminescent efficiency, i.e. the fraction of electron-hole pairs that recombine radiatively within the semiconductor. In a first approximation, the external luminescent efficiency, i.e. the fraction of electron-hole pairs that recombine radiatively to yield a photon that ultimately escapes the TPV cell, can be obtained as a function of $\eta_{\text {int }}, n_{\mathrm{s}}$ and $\rho_{\text {BR }}$ by:

$$
\eta_{\text {ext }}=\frac{1}{1-n_{s}^{2}\left(1+\rho_{B R}-2 / \eta_{\text {int }}\right)}
$$

\section{System performance with ideal TPV cells}

In this section, the TPV cells are assumed to be ideal (i.e. $\eta_{\text {int }}=1$ ) with a bandgap of $0.5 \mathrm{eV}$, which could be manufactured for instance using InGaAsSb alloys on GaSb substrates. Under this assumption, equations (2-5) and (7) are solved for the silicon parameters listed in Table I and Table II.

Table III shows the model results for the discharge of the ES system with different geometries and for two values of $\rho_{\mathrm{BR}}$ (the ideal case of $\rho_{\mathrm{BR}}=1$ and a more realistic one of $\rho_{\mathrm{BR}}=0.8$ ). Initial condition is that emitter temperature equals the silicon's melting point, so that energy is released from the system during the silicon solidification. The system is considered discharged when all silicon is solidified. Notice that the values in Table III refer to the full-power discharge mode, i.e. when the TPV converter is entirely introduced in the cavity from the beginning, which provides the highest power-to-discharge time ratio. 
Notice that these results, calculated under the assumption of adiabatic container, are valid for container walls of $10 \mathrm{~cm}$ and thermal conductivities below $0.01 \mathrm{~W} / \mathrm{m}-\mathrm{K}$ (small systems) and 0.001 $\mathrm{W} / \mathrm{m}-\mathrm{K}$ (large systems). These values are attainable by evacuated compounds (e.g. evacuated fibers or vacuum multi-foil insulation). For larger conductivities, an additional solid-liquid front will probably appear near the container wall and will distort the results obtained with this simplified model.

From Table III we conclude that total energy densities (heat plus electricity) of $\sim 1 \mathrm{MW} / \mathrm{m}^{3}$ and electric energy densities of $200-600 \mathrm{kWh} / \mathrm{m}^{3}$ are attainable in principle, which is comparable to that of best performing state of the art Li-ion batteries (Figure 4) [28], [29].

Figure 5 shows the output power as a function of time for the case of a LHTES system with $\rho_{\mathrm{BR}}=1$, $L=1 \mathrm{~m}, R_{1}=0.2 \mathrm{~m}$ and $R_{2}=0.5 \mathrm{~m}$. This particular arrangement delivers $916 \mathrm{kWh}$ of energy, from which $497 \mathrm{kWh}$ is electricity and $419 \mathrm{kWh}$ is heat. This amount of energy (heat plus electricity) is enough to power 32 Spanish dwellings (average consumption of 10,500 kWh/home-year [30]) during $24 \mathrm{~h}$. Smaller systems (microwave oven size) could be scaled to power one single home dwelling one full day (see Table III).

Another interesting feature of these systems is the very high power peak at the start of the discharge (Figure 5) in the full-power discharge mode. This peak can be used for power quality applications, such as in UPS (uninterruptible power systems), where high power is required during short periods of time.

Finally, Figure 6 shows the temperature profile through the PCM (in the radial direction) for the same TES system configuration than that of Figure 5. Notice that the very low temperature gradient in the liquid (that allows us to disregard the natural convection phenomenon) is attributed partially to the fact that most of $Q_{\mathrm{s}}$ comes from the released latent heat at the solid-liquid interface, which makes $Q_{1}$ notably smaller than $Q_{\mathrm{s}}$. A fast decrease in the emitter temperature (at $r=R_{1}=0.2 \mathrm{~m}$ ) is observed during the first instants of operation. This is related to the sharp initial drop in the electrical power shown in Figure 5. This strong drop in the emitter temperature is attributed to the decreasing area in the direction of the heat flow and to the lower thermal conductivity of the silicon's solid-phase. The lower emitter temperature, which definitively affects the output electric power, does not necessarily affect the conversion efficiency. This is true at least for TPV converters with $\rho_{\mathrm{BR}} \rightarrow 1$, for which most of sub-bandgap radiation is reflected back to the emitter. In this case, the lower emitter temperature implies a longer discharging time (due to lower radiative power) instead of lower conversion efficiency. 


\section{System performance with realistic TPV cells}

Realistic TPV cells are modeled in this work by introducing the internal and external photoluminescent efficiency, $\eta_{\text {int }}$ and $\eta_{\text {ext }}$ respectively, which account for non-radiative recombination. The best performing III-V semiconductor based PV cells have demonstrated $\eta_{\text {int }}$ and $\eta_{\text {ext }}$ values above $95 \%$ and 35\%, respectively [31]. However, semiconductors with non-direct transitions between valence band and conduction band, such as silicon, have much lower efficiencies, in the order of $\eta_{\text {ext }} \sim 0.1-1 \%$ [32]. Figure 7 shows the equivalency between $\eta_{\text {ext }}$ and $\eta_{\text {int }}$ for several values of $\rho_{\mathrm{BR}}$, according to the model used in this work. From this figure we see, for instance, that $\eta_{\mathrm{ext}}=0.01$ (optimistic case for silicon) corresponds to $\eta_{\mathrm{int}} \sim 0.2$.

Figure 8 shows the average conversion efficiency (during the full discharge of the system) as a function of the TPV cell bandgap $\left(\varepsilon_{\mathrm{G}}\right)$ for different values of $\eta_{\mathrm{int}}$ and $\rho_{\mathrm{BR}}$. For ideal BSR $\left(\rho_{\mathrm{BR}} \rightarrow 1\right)$, the conversion efficiency increases monotonically with the semiconductor's bandgap, independently of the internal luminescent efficiency. This is because most of the sub-bandgap radiation is effectively reflected back to the emitter by the BSR and do not represent a loss of energy. On the other hand, for realistic values of $\rho_{\mathrm{BR}}$, there exist an optimum bandgap which depends on both $\rho_{\mathrm{BR}}$ and $\eta_{\text {int }}$.

It is evident that high quality BSR is important for achieving high conversion efficiency. However, even for relatively low values of $\rho_{\mathrm{BR}} \sim 0.8$ we can achieve decent conversion efficiencies by utilizing high quality (i.e. $\eta_{\text {int }}>0.95$ ) low bandgap (below $0.75 \mathrm{eV}$ ) semiconductors. For instance, by utilizing semiconductors with bandgaps in the range of $0.7-0.75 \mathrm{eV}$ such as $\mathrm{GaSb}$ or InGaAs lattice matched to InP substrates, efficiencies in the range of $25-45 \%$ are achievable for BSR reflectivities in the range of $80-95 \%$. On the other hand, semiconductors with bandgaps as low as $0.5 \mathrm{eV}$ (e.g. InGaAsSb on GaSb substrates) are less sensitive to the BSR quality, with achievable efficiencies in the range of $30-45 \%$ for the same values of $\rho_{\mathrm{BR}}$. Notice that the impact of $\eta_{\text {int }}$ on the conversion efficiency is more relevant for low bandgap semiconductor, in which case having high quality material is especially relevant. However, even for "low quality" and low bandgap semiconductors such as germanium $\left(0.67 \mathrm{eV}\right.$ and assuming $\left.\eta_{\text {int }} \sim 0.2\right)$ we could obtain decent efficiencies in the range of $20-35 \%$. The lower efficiencies in this case are greatly compensated by 
the lower cost of germanium substrates if compared with other III-V substrates such as InP or GaSb (about six times cheaper).

Lastly, another possible strategy consists of using high bandgap semiconductors, in which case the impact of $\eta_{\text {int }}$ is less important and the conversion efficiency depends mostly on the BSR reflectivity. Therefore, in this case it makes more sense to use relatively "low quality" and "low cost" semiconductors such as silicon (bandgap of $1.12 \mathrm{eV}$ and $\eta_{\mathrm{int}} \sim 0.2$ ) including a very high quality BSR, in which case efficiencies in the range of $8-25 \%$ are attainable for $\rho_{\mathrm{BR}}$ in the range of 0.8-0.95. As in the case of germanium, the low efficiency is compensated by the much lower cost of the silicon devices.

In general, the use of higher bandgap semiconductors is accompanied by a decrease in the output electrical power (Figure 9), which is attributed to the poor match between the radiative spectrum and the TPV cell spectral response. For high TPV conversion efficiencies (corresponding to high BSR reflectivity) the lower power density results in a dramatic increment of the discharge time, as shown in Figure 10. This is because most of the radiative power is reabsorbed by the emitter, drastically reducing the power discharge rate.

Notice that in germanium and silicon TPV cells, the use of BSR could be challenging due to their low absorption coefficient and the consequent requirement of a thick semiconductor layer to absorb the entire incident light. This could bring too high free-electron absorption losses which drastically deteriorate the effectiveness of the BSR. In this case, an alternative solution is to use front surface filters instead of (or in combination with) a BSR.

It is worth noting that, although not considered in this paper, the use of multijunction TPV cells could represent a means of achieving higher efficiencies and power densities without the necessity of highly efficient BSR [25].

\section{Conclusions}

A conceptual LHTES system utilizing high temperature silicon PCM and thermophotovoltaic cells has been presented. The proposed TES system is fully scalable in terms of power (from $\mathrm{kW}$ to $\mathrm{MW}$ ), energy (from tens of $\mathrm{kWh}$ to tens of MWh) and discharge time (hours to days) and enables an ultra high thermal energy storage density of up to $\sim 1 \mathrm{MWh} / \mathrm{m}^{3}$. The attractiveness of this concept, besides the extreme energy density, is the possibility of using silicon as PCM, the second most abundant element on earth crust. 
A theoretical analysis describing the transient response of the system has been presented. A few different configurations have been studied in order to illustrate the system performance. This analysis has been extended to both ideal and realistic TPV cells with non-radiative recombination to provide the actual short-term potential of the concept. According to the model results, discharge efficiencies in the range of $20-45 \%$ are practically attainable depending on the TPV cell bandgap, semiconductor quality and photon recycling efficiency. This leads to electric energy densities in the range of $200-450 \mathrm{kWh}_{\mathrm{e}} / \mathrm{m}^{3}$, which is comparable to the best performing state of the art Li-ion batteries.

\section{Acknowledgment}

Authors acknowledge the financial support of the Comunidad de Madrid through the Programme MADRID-PV (Grant number S2013/MAE-2780) and from the Spanish Ministerio de Economía y Competititvidad through the Project PROMESA (grant N. ENE2012-37804-C02-01). 


\section{References}

[1] A. Gil, M. Medrano, I. Martorell, A. Lázaro, P. Dolado, B. Zalba, and L. F. Cabeza, "State of the art on high temperature thermal energy storage for power generation. Part 1 -Concepts, materials and modellization," Renew. Sustain. Energy Rev., vol. 14, no. 1, pp. 31-55, Jan. 2010.

[2] K. Nithyanandam and R. Pitchumani, "Cost and performance analysis of concentrating solar power systems with integrated latent thermal energy storage," Energy, vol. 64, pp. 793-810, Jan. 2014.

[3] F. Agyenim, N. Hewitt, P. Eames, and M. Smyth, "A review of materials, heat transfer and phase change problem formulation for latent heat thermal energy storage systems (LHTESS)," Renew. Sustain. Energy Rev., vol. 14, no. 2, pp. 615-628, Feb. 2010.

[4] W. Su, J. Darkwa, and G. Kokogiannakis, "Review of solid-liquid phase change materials and their encapsulation technologies," Renew. Sustain. Energy Rev., vol. 48, pp. 373-391, Aug. 2015.

[5] H. L. Zhang, J. Baeyens, J. Degreve, G. Caceres, R. Segal, and F. Pitie, "Latent heat storage with tubular-encapsulated phase change materials (PCMs)," Energy, vol. 76, pp. 66-72, Nov. 2014.

[6] D. Fernandes, F. Pitie, G. Caceres, and J. Baeyens, “Thermal energy storage: 'How previous findings determine current research priorities," Energy, vol. 39, no. 1, pp. 246-257, Mar. 2012.

[7] T. Bauer, W. D. Steinmann, D. Laing, and R. Tamme, "Thermal energy storage materials and systems," in Annual review of Heat Transfer, vol. 15, Begell House, Inc., pp. 131-177.

[8] J. W. Raade and D. Padowitz, "Development of Molten Salt Heat Transfer Fluid With Low Melting Point and High Thermal Stability," J. Sol. Energy Eng., vol. 133, no. 3, pp. 031013031013, Jul. 2011.

[9] T. Bauer, Thermophotovoltaics: Basic Principles and Critiical Aspects of System Design. Springer, 2011.

[10] D. L. Chubb, Fundamentals of thermophotovoltaic energy conversion. Elsevier, 2007.

[11] G. N. Hatsopoulos and E. P. Gyftopoulos, Thermionic Energy Conversion, 2 vols. Cambridge, Massachusetts: The MIT Press, 1979.

[12] A. Datas, "Hybrid thermionic-photovoltaic converter," Appl Phys Lett, vol. 108, no. 14, p. 143503, Apr. 2016.

[13] D. L. Chubb, B. S. Good, and R. A. Lowe, "Solar thermophotovoltaic (STPV) system with thermal energy storage," 1995, pp. 181-198.

[14] A. Datas, D. L. Chubb, and A. Veeraragavan, "Steady state analysis of a storage integrated solar thermophotovoltaic (SISTPV) system," Sol. Energy, vol. 96, pp. 33 - 45, 2013.

[15] A. Veeraragavan, L. Montgomery, and A. Datas, "Night time performance of a storage integrated solar thermophotovoltaic (SISTPV) system," Sol. Energy, vol. 108, no. 0, pp. 377389, Oct. 2014.

[16] M. R. Reid, D. B. Scharfe, and R. N. Webb, "Computational evaluation of a latent heat energy storage system," Sol. Energy, vol. 95, pp. 99-105, Sep. 2013.

[17] M. R. Gilpin, D. B. Scharfe, and M. P. Young, "Phase-Change Thermal Energy Storage and Conversion: Development and Analysis for Solar Thermal Propulsion," presented at the 48th AIAA/ASME/SAE/ASEE Joint Propulsion Conference \& Exhibit, Atlanta, GE (US), 2012.

[18] M. R. Gilpin, D. B. Scharfe, M. P. Young, and A. P. Pancotti, "Molten Boron Phase-Change Thermal Energy Storage to Augment Solar Thermal Propulsion Systems," presented at the 47th AIAA Joint Propulsion Conference, San Diego, CA (US), 2011. 
[19] M. Emziane and M. Alhosani, "Sensitivity analysis of a solar thermophotovoltaic system with silicon thermal storage," in 2014 3rd International Symposium on Environmental Friendly Energies and Applications (EFEA), 2014, pp. 1-5.

[20] Matthew R, Gilpin, D. B. Scharfe, M. P. Young, and R. N. Webb, "High Temperature Latent Heat Thermal Energy Storage to Augment Solar Thermal Propulsion for Microsatellites," Mar. 2014.

[21] R. W. Olesinski and G. J. Abbaschian, "The B-Si (Boron-Silicon) system," Bull. Alloy Phase Diagr., vol. 5, no. 5, pp. 478-484, Oct. 1984.

[22] G. V. Samsonov and V. M. Sleptsov, "Preparation of boron-silicon alloys," Sov. Powder Metall. Met. Ceram., vol. 3, no. 6, pp. 488-496, Nov. 1964.

[23] R. B. Peterson, "A concept for storing utility-scale electrical energy in the form of latent heat," Energy, vol. 36, no. 10, pp. 6098-6109, Oct. 2011.

[24] A. Datas, A. Martí, C. del Cañizo, and A. Luque, "Electric energy storage system," WO2015132305 A1.

[25] A. Datas, "Optimum semiconductor bandgaps in single junction and multijunction thermophotovoltaic converters," Sol. Energy Mater. Sol. Cells, vol. 134, no. 0, pp. 275 - 290, 2015.

[26] A. Schei, J. Tuset, and H. Tveit, High silicon alloys. Trondheim: Tapir Forlag, 1998.

[27] Y. B. Magomedov and G. G. Gadjiev, "High-temperature thermal conductivity of silicon in the solid and liquid states," High Temp., vol. 46, no. 3, pp. 422-424, May 2008.

[28] H. Chen, T. N. Cong, W. Yang, C. Tan, Y. Li, and Y. Ding, "Progress in electrical energy storage system: A critical review," Prog. Nat. Sci., vol. 19, no. 3, pp. 291-312, Mar. 2009.

[29] X. Luo, J. Wang, M. Dooner, and J. Clarke, "Overview of current development in electrical energy storage technologies and the application potential in power system operation," Appl. Energy, vol. 137, pp. 511-536, Jan. 2015.

[30] "Análisis del consumo energético del sector residencial en España," IDAE, 2011.

[31] M. A. Steiner, J. F. Geisz, I. Garcia, D. J. Friedman, A. Duda, W. J. Olavarria, M. Young, D. Kuciauskas, and S. R. Kurtz, "Effects of Internal Luminescence and Internal Optics on and of III-V Solar Cells," IEEE J. Photovolt., vol. 3, no. 4, pp. 1437-1442, Oct. 2013.

[32] M. A. Green, J. Zhao, A. Wang, P. J. Reece, and M. Gal, "Efficient silicon light-emitting diodes," Nature, vol. 412, no. 6849, pp. 805-808, Aug. 2001.

[33] R. C. Wheast, CRC Handbook of chemistry and physics. West Palm Beach: CRC Press, 1973. 
TABLE I

SILICON THERMAL PROPERTIES

\begin{tabular}{|l|c|c|}
\hline \multicolumn{1}{|c|}{ property } & sym & value \\
\hline Latent heat of fusion & $L_{\mathrm{f}}$ & $1800 \mathrm{~J} / \mathrm{g}$ \\
\hline Thermal conductivity (solid) & $k_{\mathrm{s}}$ & $25 \mathrm{~W} / \mathrm{m}-\mathrm{K}$ \\
\hline Thermal conductivity (liquid) & $k_{1}$ & $50 \mathrm{~W} / \mathrm{m}-\mathrm{K}$ \\
\hline Density (solid \& liquid) & $\rho_{\mathrm{l}}=\rho_{\mathrm{s}}$ & $2520 \mathrm{~kg} / \mathrm{m}^{3}$ \\
\hline Heat capacity (solid \& liquid) & $c_{\mathrm{ps}}=c_{\mathrm{pl}}$ & $1040 \mathrm{~J} / \mathrm{kg}-\mathrm{K}$ \\
\hline Melting point & $T_{\mathrm{m}}$ & $1680 \mathrm{~K}$ \\
\hline
\end{tabular}

TABLE II

OTHER SYSTEM PARAMETERS

\begin{tabular}{|l|c|c|}
\hline \multicolumn{1}{|c|}{ property } & sym & value \\
\hline TPV cell bandgap & $\varepsilon_{\mathrm{G}}$ & sweep param \\
\hline TPV cell BSR reflectivity & $\rho_{\mathrm{BR}}$ & sweep param \\
\hline TPV cell internal photoluminescent efficiency & $\eta_{\text {int }}$ & sweep param \\
\hline TPV cell temperature & $T_{\mathrm{c}}$ & 300 K \\
\hline TPV cell voltage & $V$ & optimized \\
\hline PCM length & $L^{\prime}$ & sweep param \\
\hline PCM inner radius & $R_{1}$ & sweep param \\
\hline PCM outer radius & $R_{2}$ & sweep param \\
\hline
\end{tabular}


TABLE III

ENERGY STORAGE SYSTEM OUTPUT CHARACTERISTICS

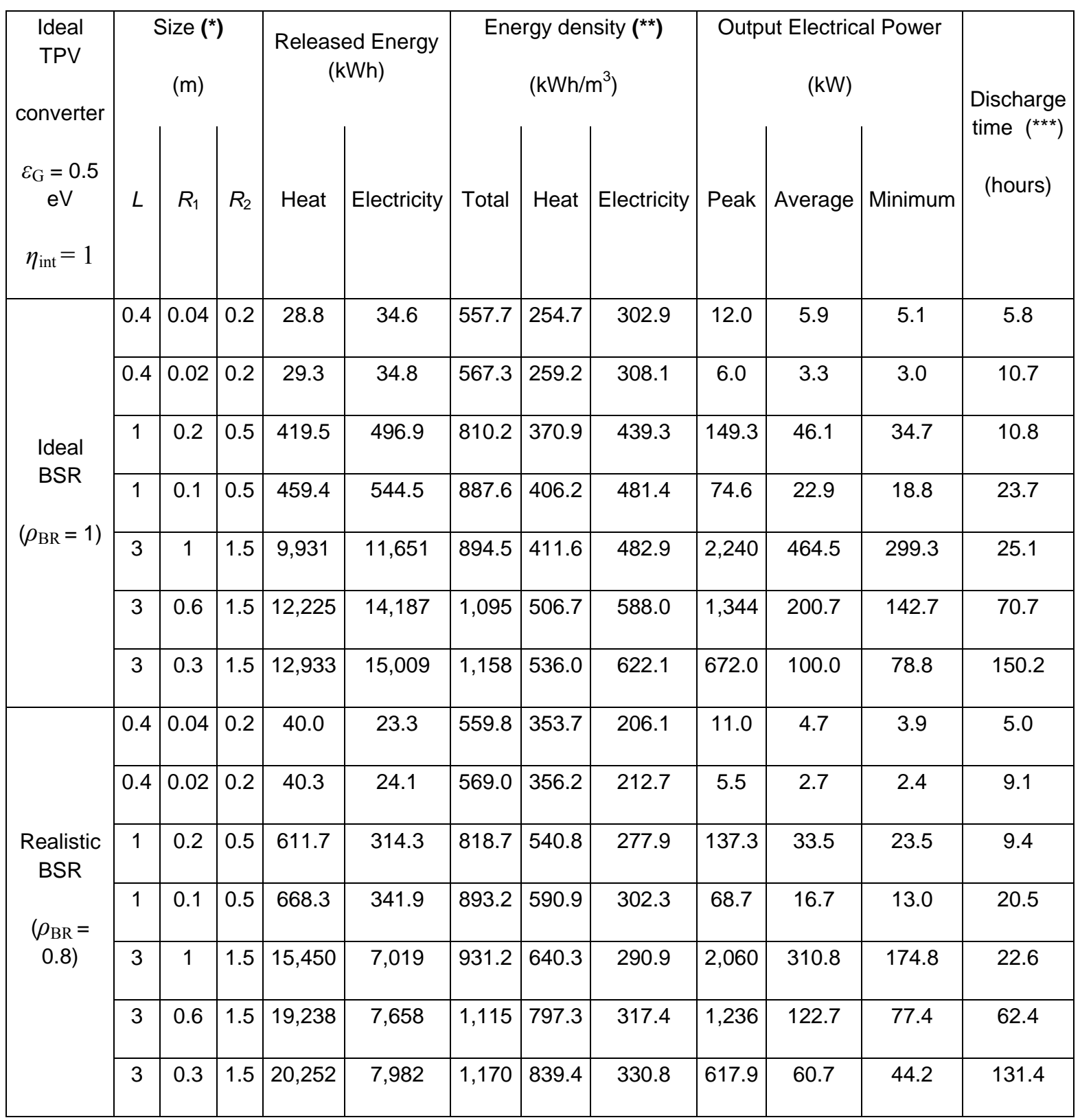

$\left({ }^{*}\right)$ Outer vessel walls are assumed to be $10 \mathrm{~cm}$ thick in all the cases, $R_{1}$ is the inner cylinder radius, $L$ is the cylinder length and $R_{2}$ is the outer radius (not considering the vessel walls thickness). $\left({ }^{* *}\right)$ total system volume is $\pi L\left(R_{2}+0.1\right)^{2}\left({ }^{* *}\right)$ full-power discharge. 


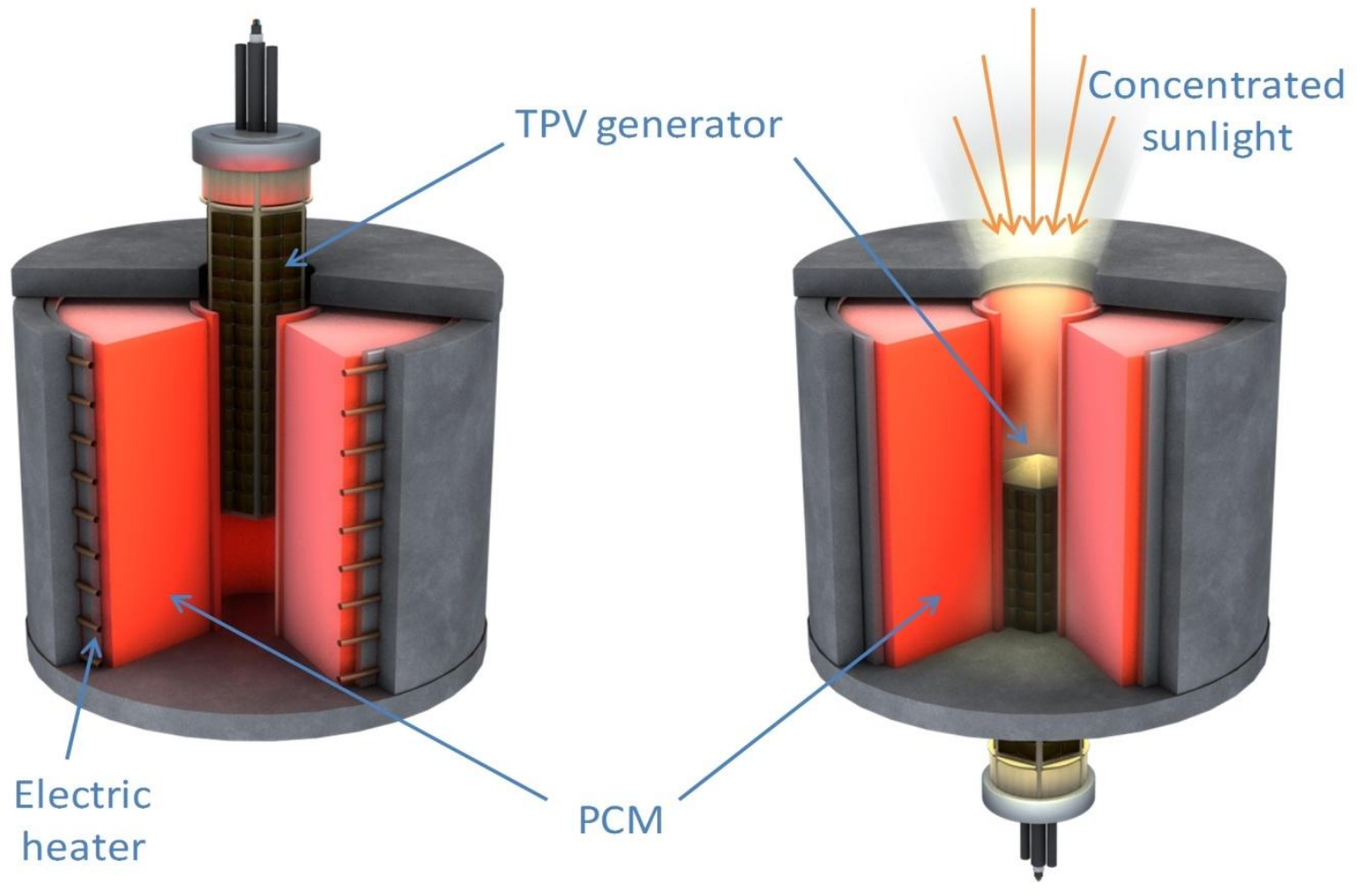

Figure 1. Electric-LHTES (left) and solar-LHTES (right) systems utilizing high melting point PCM and thermo-photovoltaic (TPV) cells for electricity production [24]. 


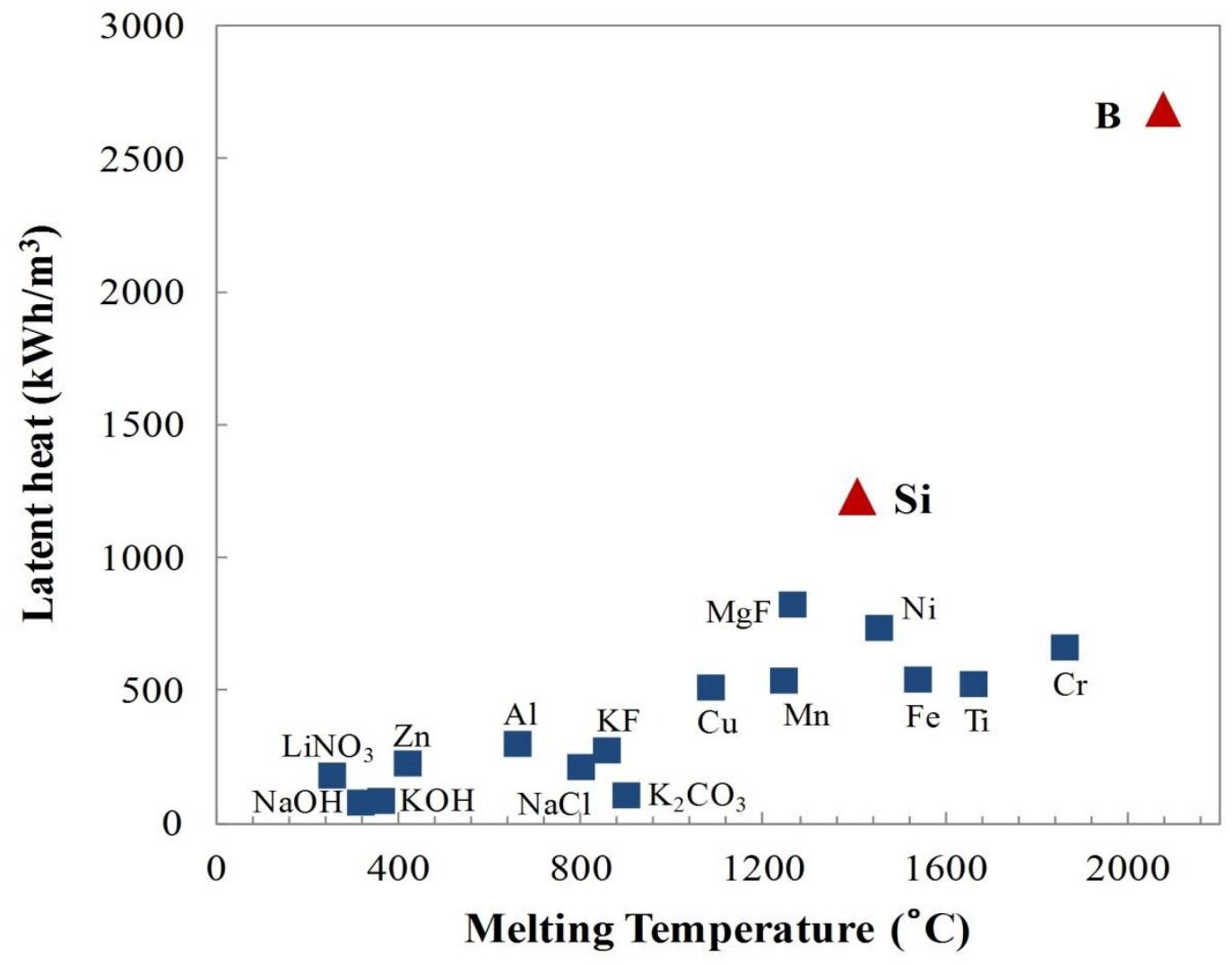

Figure 2. Latent heat of fusion of different materials as a function of the melting temperature [3], [4], [33]. 


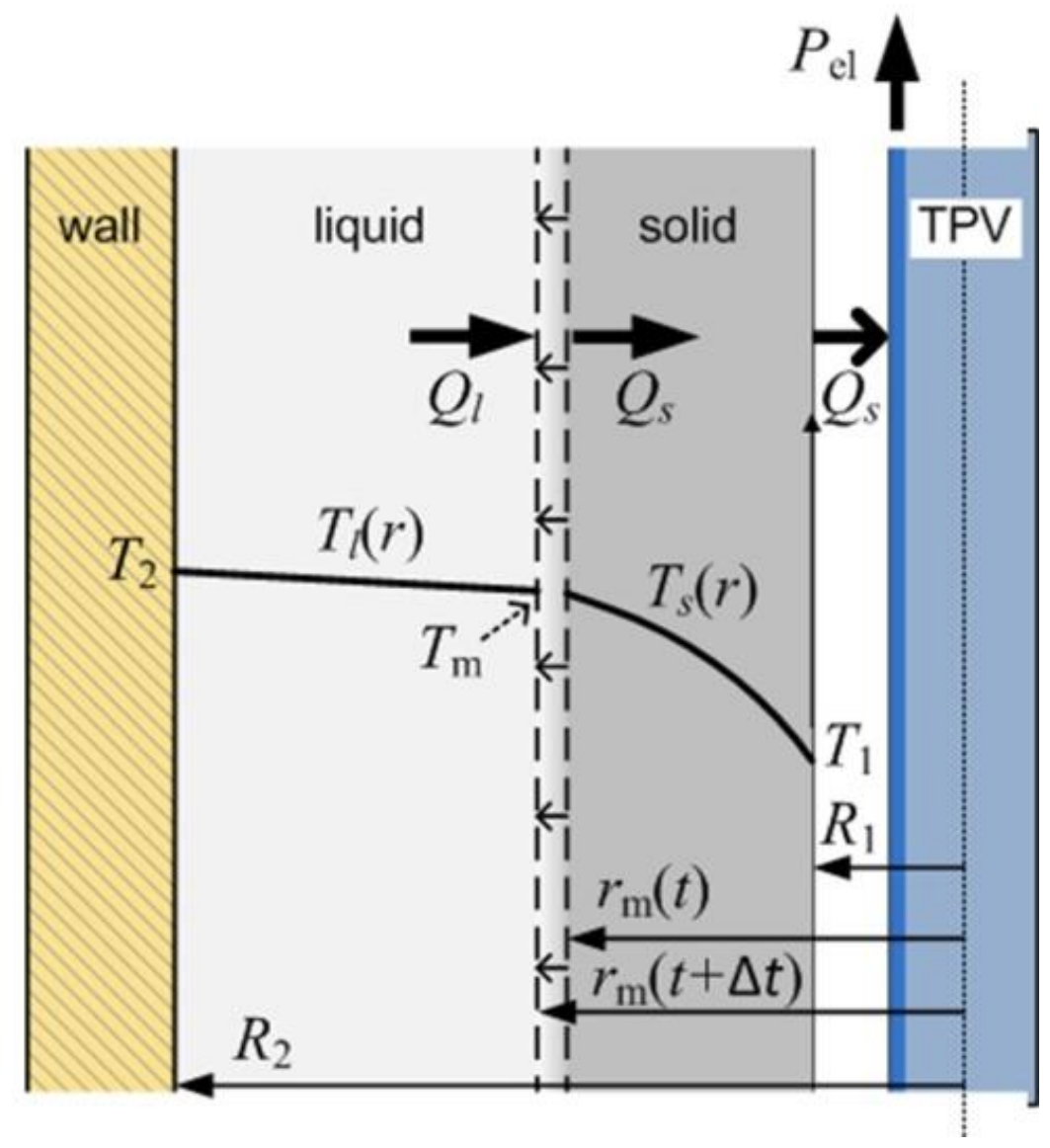

Figure 3. Cross-sectional view of the LHTES system illustrating the heat transfer from the liquid PCM to the TPV converter and the resultant temperature distribution. 


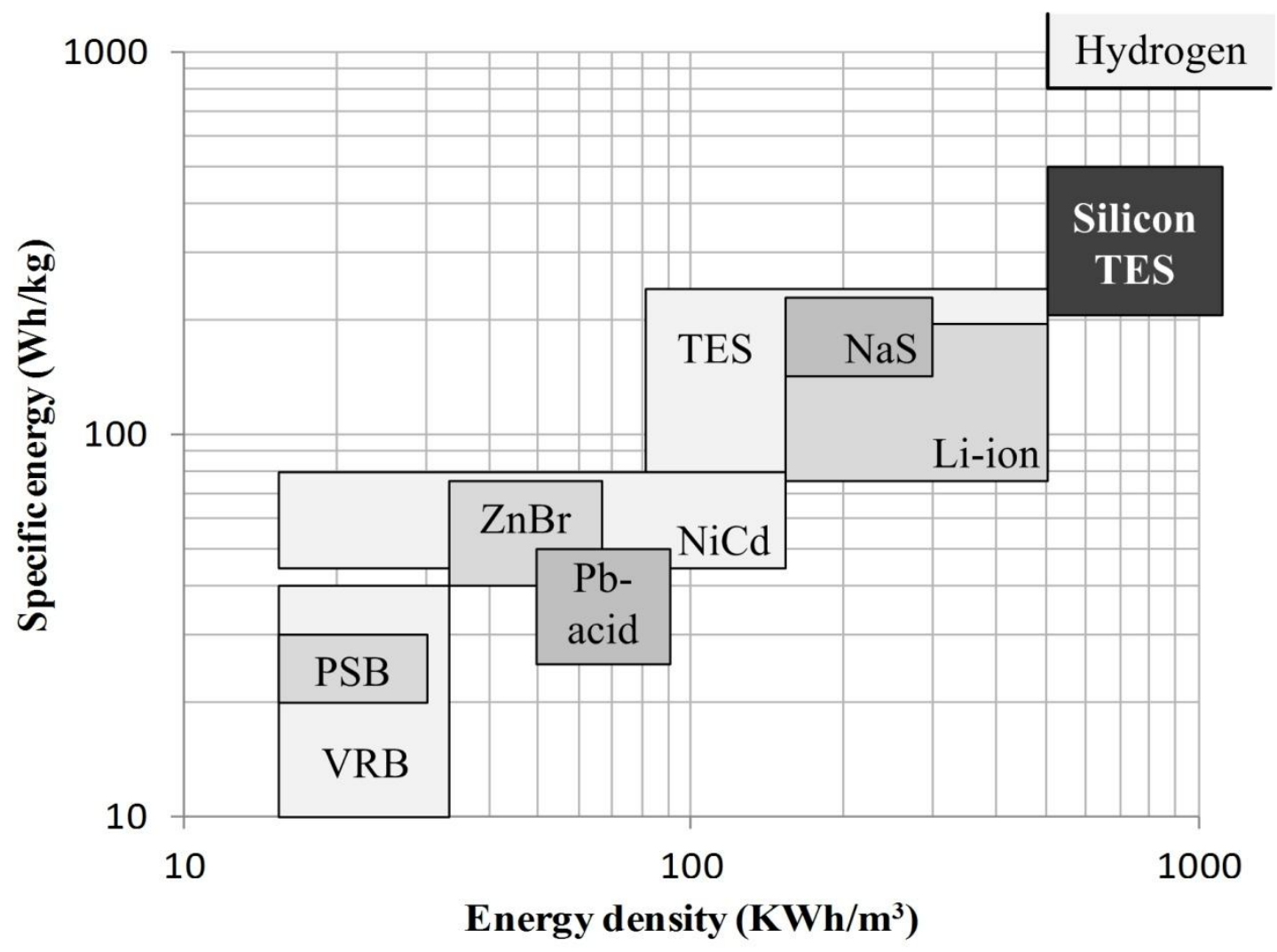

Figure 4. Specific energy and energy density of several energy storage systems (taken from [28], [29]). Silicon-TES reefers to the system analyzed in this work. 


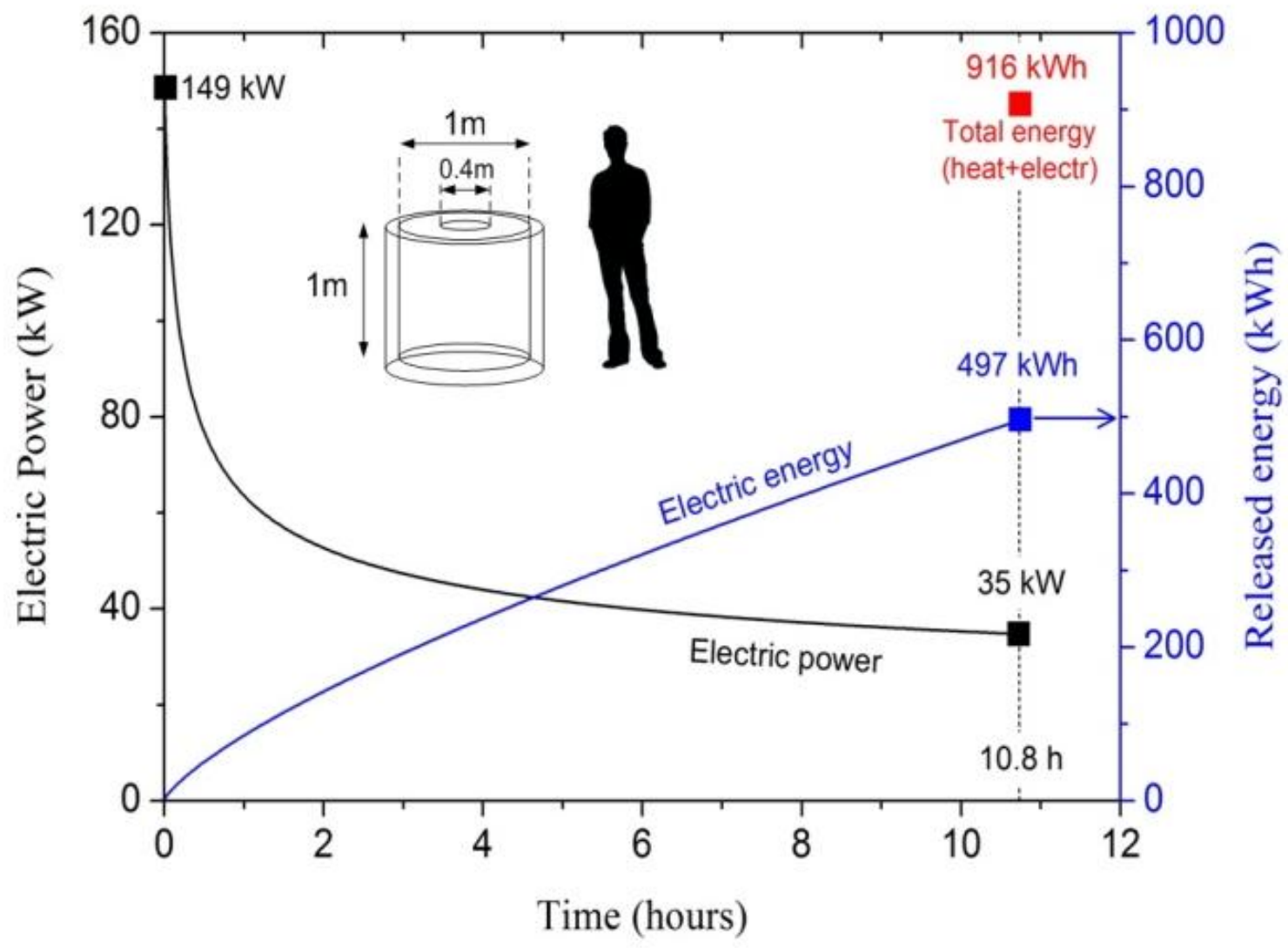

Figure 5. Output power as a function of time during the discharge of an LHTES system ( $L=1 \mathrm{~m}, R_{1}=0.2 \mathrm{~m}, R_{2}=0.5 \mathrm{~m}$ and ideal $0.5 \mathrm{eV}$ TPV cells, i.e. $\eta_{\mathrm{int}}=1$ and $\rho_{\mathrm{BR}}=1$ ). This result represents the full-power discharge mode, i.e. the TPV converter is entirely introduced in the cavity from the beginning. 


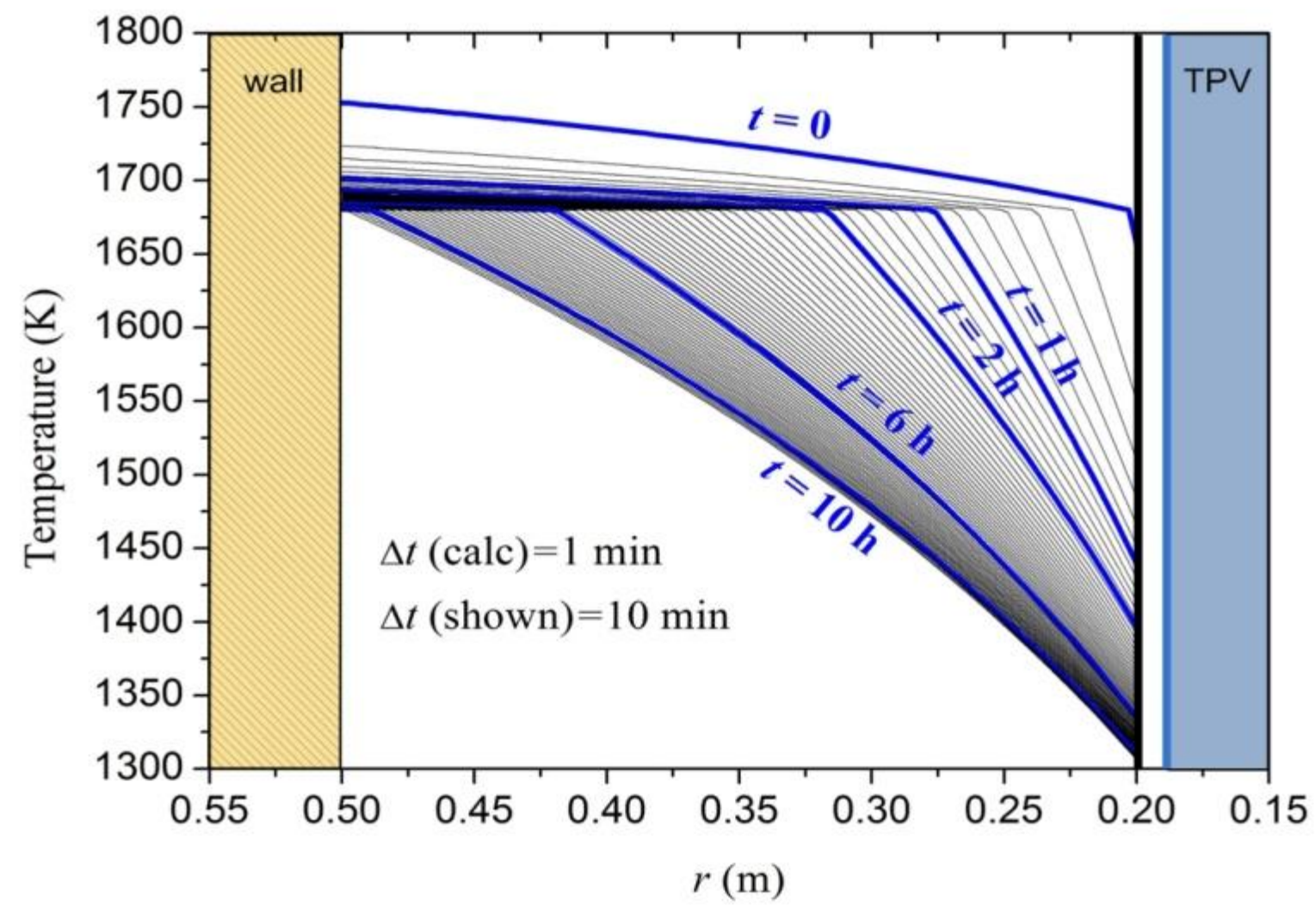

Figure 6. Temperature profile in the silicon PCM as a function of time for the LHTES system corresponding to the result shown in Figure $5\left(L=1 \mathrm{~m}, R_{1}=0.2 \mathrm{~m}, R_{2}=0.5 \mathrm{~m}\right.$ and ideal $0.5 \mathrm{eV}$ TPV cells, i.e. $\eta_{\text {int }}=1$ and $\rho_{\mathrm{BR}}=1$ ). 


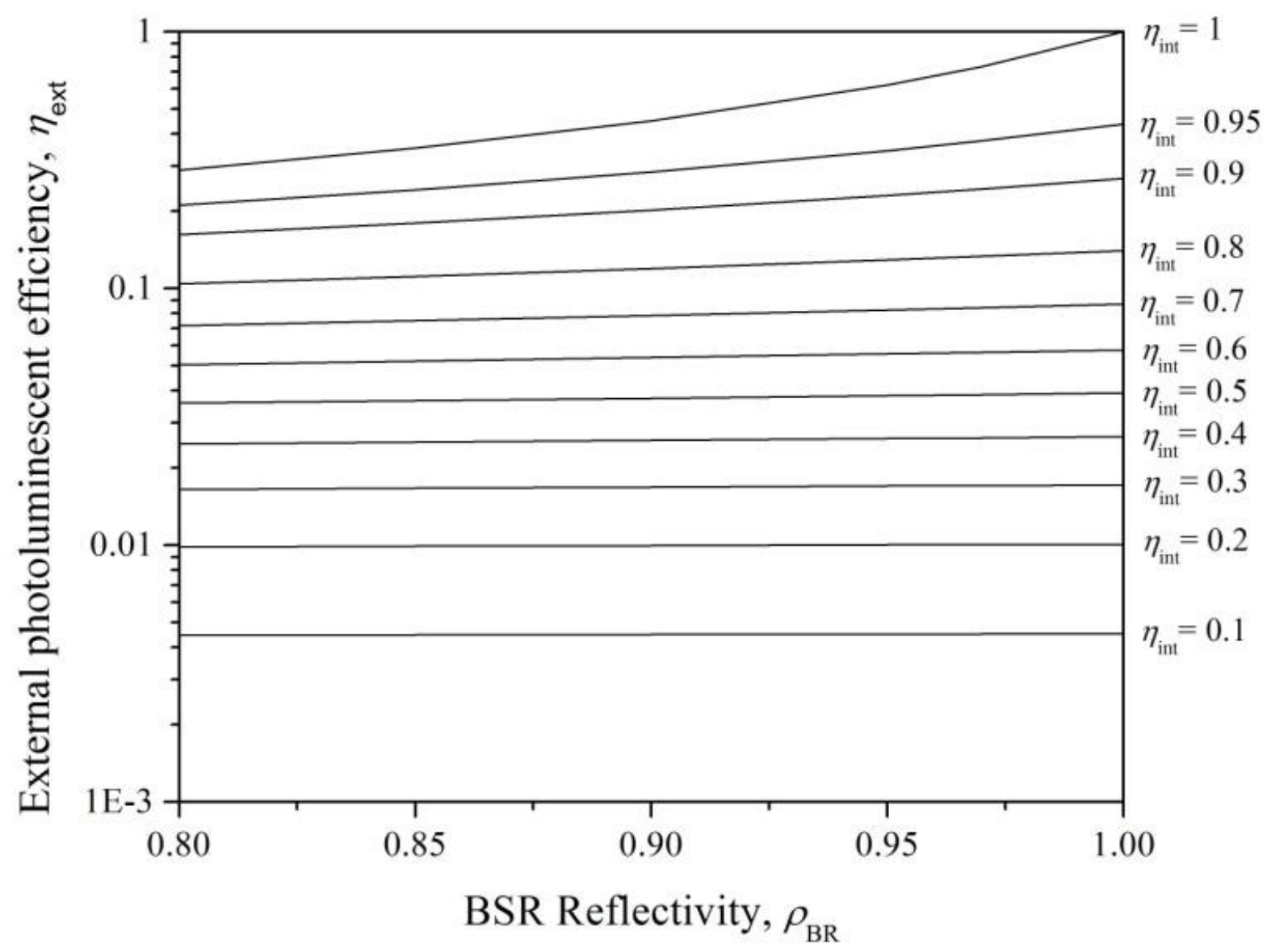

Figure 7. External photoluminescent efficiency as a function of the BSR reflectivity and the internal photoluminescent efficiency. State of the art (lattice matched) GaAs solar cells have demonstrated $\eta_{\text {int }} \sim 0.97$. Silicon LEDs have demonstrated $\eta_{\text {ext }} \sim 0.01$. 


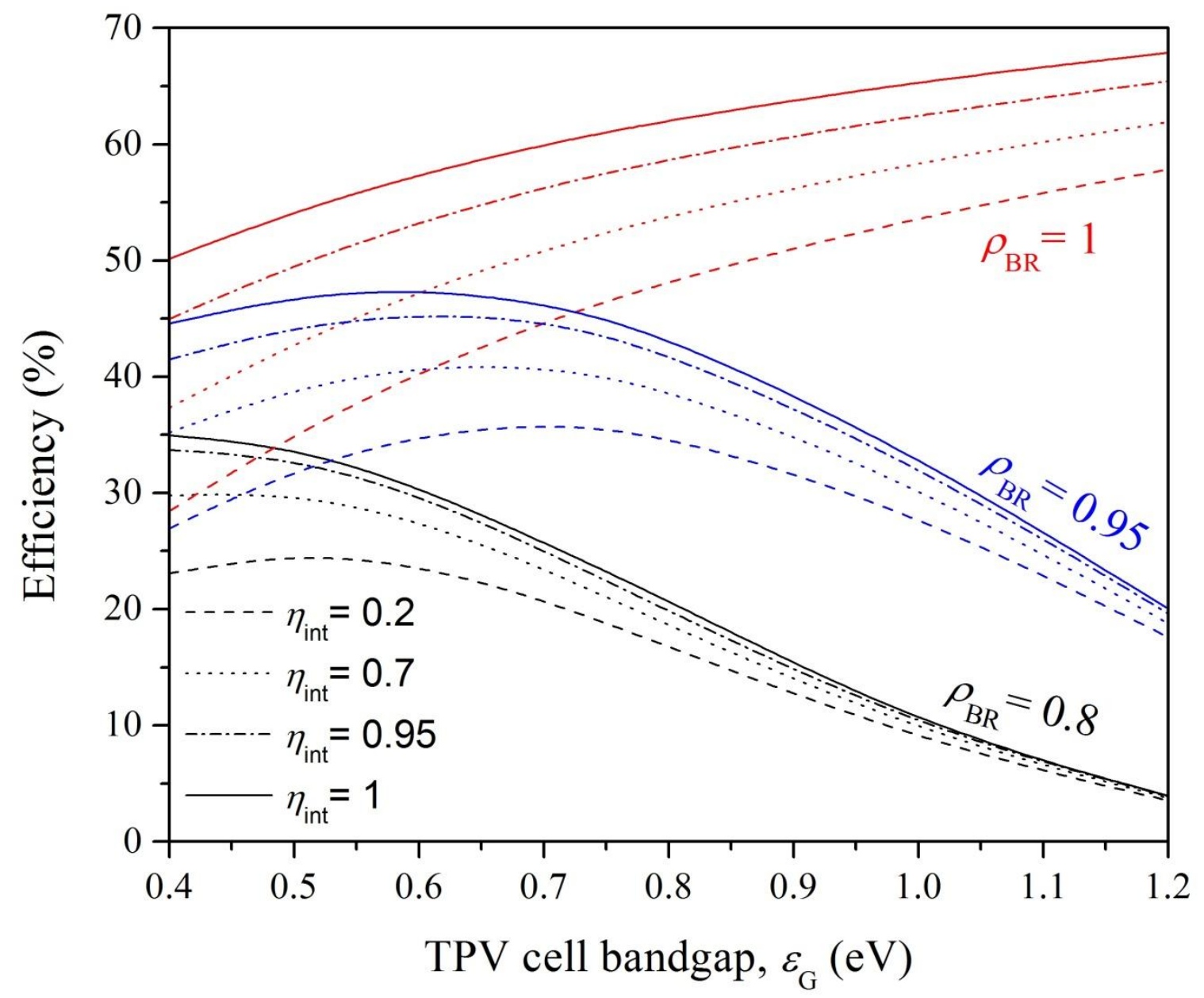

Figure 8. Average heat-to-electricity conversion efficiency during the discharge of the LHTES system as a function of the TPV cell bandgap, the BSR reflectivity and the internal photoluminescent efficiency. The LHTES system has the following configuration parameters: $L=1 \mathrm{~m}, R_{1}=0.2 \mathrm{~m}, R_{2}=0.5 \mathrm{~m}$. 


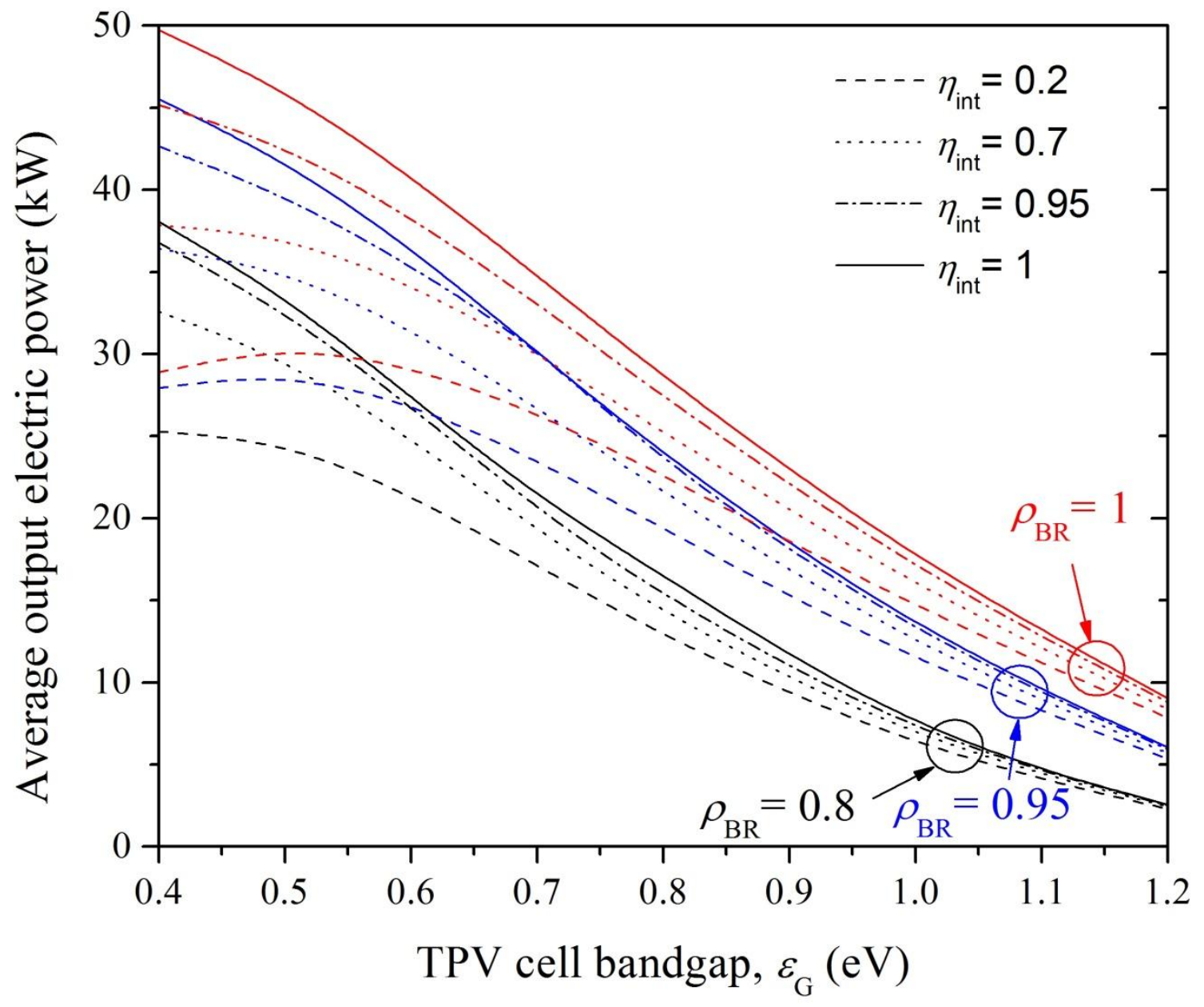

Figure 9. Average output electric power as a function of the TPV cell bandgap, the BSR reflectivity and the internal photoluminescent efficiency. The LHTES system has the following configuration parameters: $L=1 \mathrm{~m}, R_{1}=0.2 \mathrm{~m}, R_{2}=0.5 \mathrm{~m}$. The average electric power density, in $\mathrm{kW}$ per $\mathrm{m}^{2}$ of TPV cell area, is obtained dividing the data of this Figure (in $\mathrm{kW}$ ) by the total TPV cell area of $2 \pi L R_{1}=1.26 \mathrm{~m}^{2}$. For instance, an average output power of $25 \mathrm{~kW}$ corresponds to an average output power density of $\sim 2 \mathrm{~W} / \mathrm{cm}^{2}$. 


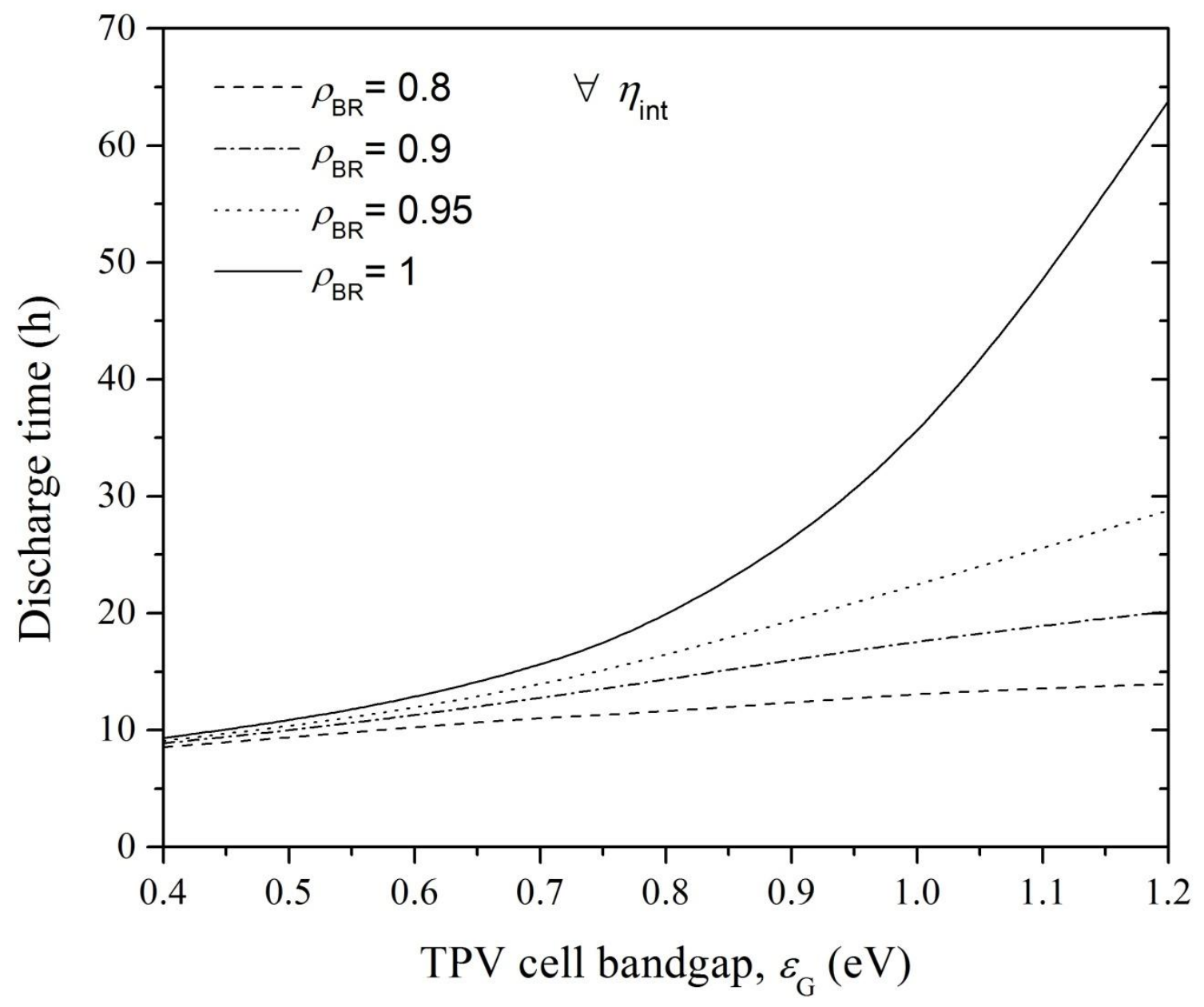

Figure 10. Discharge time of the LHTES system as a function of the TPV cell bandgap, the BSR reflectivity and the internal photoluminescent efficiency. The LHTES system has the following configuration parameters: $L=1 \mathrm{~m}, R_{1}=0.2 \mathrm{~m}, R_{2}=0.5 \mathrm{~m}$. (results are almost independent of $\left.\eta_{\text {int }}\right)$. 